\title{
eHealth Adoption and its Impact on Life Expectancy : A Comparative Study of Selected BRICS Countries plus TWO
}

\author{
Ebenezer Larnyo ${ }^{1 *}$, Baozhen Dai ${ }^{1}$, Abigail Larnyo², Christabel Seyram Ankah ${ }^{3}$ \\ ${ }^{1}$ Department of Health Policy and Management, Jiangsu University, School of Management, 301 Xuefu Road, \\ Zhenjiang, Jiangsu Province, China. \\ 2 Faculty of Applied Sciences, University of Ghana, Legon \\ ${ }^{3}$ Department of Computer Science, Kwame Nkrumah University of Science and Technology, Kumasi \\ *e-mail: larnyoebenezer@yahoo.com
}

\begin{abstract}
The relationship between eHealth adoption and life expectancy is complex. Research outcomes show different and contradictory results on this relationship. How and why eHealth adoption affect life expectancy is still to a large extent not clear. A causal link between the two is yet to be proven. Without such knowledge, effects of increase or decrease in eHealth adoption on life expectancy may be overestimated or underestimated. Thus, this study seeks to analyze the relationship between life expectancy at birth and eHealth adoption amongst five selected countries; 3 BRICS countries (China, Russia and South Africa), USA and Ghana, taking into account eHealth foundations, electronic health records, use of health eLearning in health sciences, social media and big data.

This cross-sectional study analyzed WHO Global Survey on eHealth data of the five selected countries collected between April and August 2015 by calculating and describing the bivariate correlation between the dependent variable and independent variables. A forward linear regression analysis is also applied to determine the predictive capability of the model.

A significant negative correlation was observed between total health expenditure and eLearning overview, ICT development index rank and internet users and between life expectancy at birth and social media with coefficients of $r s=-0.95, p=.014, r s=-1.00, p<.001$ and $r s=-0.96, p<.001$ respectively. Apart from social media indicator of eHealth's eLearning overview that was significantly correlated with life expectancy at birth, no other correlation was observed between life expectancy at birth and any of the indicators of eHealth. The regression analysis of the predictors showed a near perfect result of $100 \%$ predictive ability of the model. The study observed that countries that incorporated social media into their eHealth actions; through the promotion of health messages on social media as a part of health promotion campaigns, managing patient appointments, sought feedback on services, and made general health announcements on social media, turn to have citizens that have a significant longer life expectancy. In order to realize high life expectancy of citizens, policy measures have to be directed toward investments in social media incorporation into eHealth strategies.
\end{abstract}

Keywords : eHealth, Life expectancy, Social media, BRICS countries, USA, Ghana

\section{INTRODUCTION}

Sustainable health care provision, increasing life expectancy, improving survival in people with acute and long-term conditions and a greater array of available treatment options are combining to place an increasing burden on governments and health care 
organizations globally. This situation is particularly true for most developing and developed economies, where issues of high salary for health professionals, coupled with public pressure for an improved public sector performance and at the same time containing expenditure growth are seemingly unending. In recognizing the role eHealth plays in achieving universal health care especially in developing economies, the World Health Assembly's 2005 resolution christened "WHA58.28" defined eHealth as the cost-effective and secure use of ICT in support of health and health-related fields, including health-care services, health surveillance, health literature, and health education, knowledge and research. The adoption and implementation of eHealth in primary health care settings have resulted in time saving, improved access to results and data, decreased staff working time, greater accuracy, and increased ease and speed when retrieving patient data, provided equitable, essential healthcare for all through patient centeredness, evidence-based medicine, and prevention and health promotion (WHO 1978, Flygt, Homelius et al. 1995, Wager, Lee et al. 2000, Pizziferri, Kittler et al. 2005, Van Lerberghe 2008, Fontaine, Ross et al. 2010). eHealth has tremendous potential in helping achieve the UN's desire for a universal health coverage (WHO 1978). For instance, it helps provide services to remote populations and underserved communities through the use of telehealth or mHealth. It also facilitates the training of the health workforce through the use of eLearning, and makes education more widely accessible especially for those who live in isolated and deserted towns and villages. The incorporation of eHealth into care delivery enhances patient diagnosis and treatments by providing accurate and timely patient information through electronic health records. Through the strategic use of ICT, eHealth has improved the operations and financial efficiency of health care systems in countries that have adopted them. Research has shown that not only can key health investments such as eHealth have a

potential in increasing productivity, but also impressive health outcomes. It is said that citizens in good health have higher productivity. Research has also shown that higher spending in the health care sector by governments, mostly computed as a percentage of the Gross Domestic Product (GDP), is related to better health outcomes, such as high life expectancy and lower infant mortality (Kim and Lane 2013, van den Heuvel and Olaroiu 2017). Another study by Piotr Arak et. al. 2018 revealed that, there is a ratio of 2:1 return on investment when eHealth adoption benefits were given a euro value, with a five years average breakeven point for the ten eHealth initiatives studied. They projected that on an average, these solutions could decrease the health expenditures of most European countries by $0.31 \%$ of their GDPs or decrease by $5 \%$ less of their expenditure on health which is mostly financed by the taxpayer.

While there are evidences of how quickly eHealth has become a symbol of democratization healthcare; providing an avenue to eradicate the challenges caused by ageing society, the burden of epidemics of non-communicable and chronic diseases as well as reducing the astronomically rising costs of healthcare, research on its impact on life expectancy in developed and developing countries such as those in BRICS (Brazil, Russia, India, China and South Africa), sub-Saharan Africa like Ghana, and developed nations like United States of America is still an emerging topic.

Life expectancy at birth is one of the most frequently used indicators when it comes to assessing the health status of individuals in a particular society, community or nation. Gains in Life expectancy at birth can be attributed to a number of factors, including rising living standards, improved lifestyle and better education, as well as greater access to quality health services.

\subsection{Life Expectancy in BRICS}


Average life expectancy in BRICS stands at a fraction below the global mean, though it varies from 62.9 in South Africa to 76.1 in China (WHO 2015, 2017). Steady increases in life expectancy since 1960 in Brazil and India contrast to an accelerated increase in China between the 1960s and 1980s. This has been mainly due to well-targeted public health campaigns that reduced infant and child mortality and communicable disease; and improved economic conditions impacting nutrition, education and distribution of health services (WHO 2017). Life expectancy gains from the 1960s onwards in South Africa were largely lost during the 1990s but it has increased annually since 2005, however, fluctuation and stagnation has meant the Russian Federation has gained less than five years in life expectancy since 1960. These disparities may be predominantly due to how these countries differ in terms of natural resource endowment, level of industrialization, relative impact on the global economy and health care expenditures which ultimately will impact on their desire to adopt eHealth.

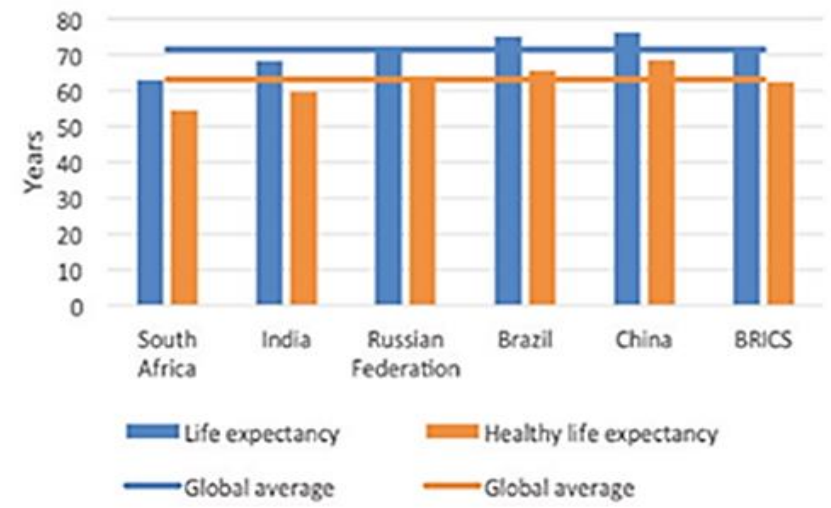

Figure 1. Life expectancy and healthy life expectancy across BRICS (WHO 2017)

For an effective health policy in BRICS if it truly seeks to achieve universal healthcare delivery and ultimately increase the life expectancy amongst its citizenry, it is important to understand whether and how the eHealth and other investments in eHealth affect the life expectancy of the BRICS plus Two population. Thus, this study explores and analyzes the relationship between eHealth and life expectancy taking into account eHealth foundations, electronic health records, use of health eLearning in health sciences, social media and big data.

\section{METHODS AND MATERIAL}

Secondary data from the third global survey on eHealth conducted by the WHO Global Observatory for eHealth (GOe) focused on the use of eHealth in support of universal health coverage collected on 125 WHO Member States between April and August 2015 was used to analyze eHealth adoption among the five selected countries which included eight key indicators; eHealth foundations, legal frameworks on eHealth, TeleHealth, electronic health records, use of health eLearning in health sciences, mHealth, social media and big data. The survey responses were based on selfreporting by a selected group of eHealth experts for each participating country.

While every effort was made by countries to select the best national experts to complete the instrument, it was not possible to determine whether they had the collective eHealth knowledge to answer each question (WHO 2016). Similarly, while survey responses were checked for consistency and accuracy, it was not possible to verify all responses to every question. Thus, as a measure to ensure quality assurance of the responses, the surveys received from participating countries were reviewed for completeness. External sources of information were used for validation of the data and to resolve inconsistencies (WHO 2016). Data were reviewed before entry and after layout for publication. Data from WHO on life expectancy for 2015 was also used for the analysis.

This study used five out of the eight indicators; eHealth foundations which has to do with, electronic health records, use of health eLearning in health sciences, social media and big data. Data were assessed 
using Pearson correlations and multiple linear regression. IBM SPSS version 22 was used to perform the data analysis, setting the significance (alpha) level at 0.05 .

\section{RESULTS AND DISCUSSION}

\subsection{Descriptive Results of Countries}

The country descriptive shows indicators of physician density (per 10000 population), nurse and midwife density (per 10000 population), life expectancy, total expenditure on health expressed as percentage of GDP, mobile-cellular subscription expressed as a percentage of the total population of the respective countries, and the percentage of the population that uses internet.

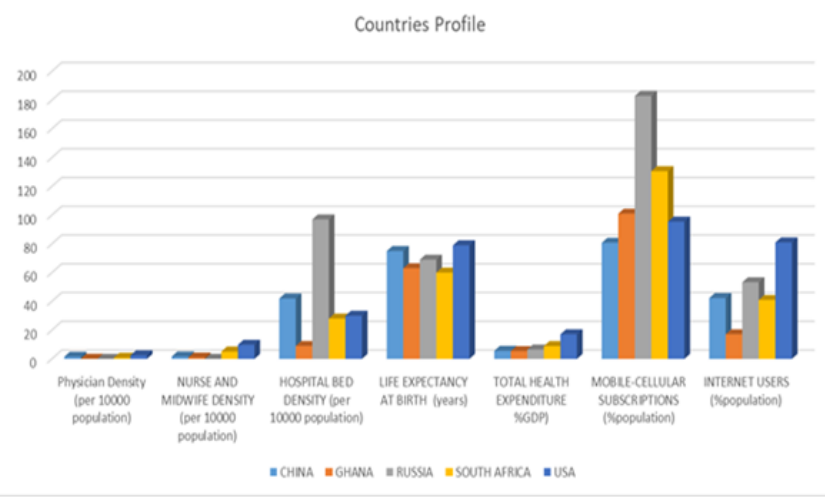

Figure 2. Countries Profile of Selected BRICS plus TWO

In terms of physician density expressed per 10,000 population, USA had the highest number with 2.45 , with China occupying the second position with 1.49. Physician density for Ghana and South African was 0.1 and 0.78 respectively with no response for Russia. USA and South Africa both had the highest in terms of nurse and midwife density per 10,000 population with 9.82 and 5.11 respectively while China and Ghana had 1.66 and 0.93 respectively. China and USA both had the highest life expectancy at birth with 79 and 75 respectively, with just a 3 years gap between the two, while those for Russia, South Africa and Ghana were
69, 63 and 60 respectively. The United States spent 17.1 percent of their total GDP on health, followed by South Africa with 8.9\%, Russia 6.5\%, China 5.6\% and Ghana $5.4 \%$. One key driver of eHealth in any country of the world is the level of use of mobile phone and access of internet by citizens. A cursory look at the mobile-cellular subscription rate of the five selected countries showed a percentage of 182.92 for Russia, 130.56 for South Africa, $100.99 \%$ for Ghana, $95.45 \%$ for USA and $80.76 \%$ for China. The lower comparative percentage for China and USA may be due to the huge population in those country since the mobile-cellular subscription rate is expressed as a percentage of the total population. Finally, the country outlook for internet usage in terms of the percentage of the individual countries population was largely encouraging except for Ghana which had about 17.1\% of their total population having access to internet. USA's internet users were $81 \%$ of their population while Russia, China and South Africa were 53.3\%, 42.3\% and $41 \%$ respectively (see figure 2 ).

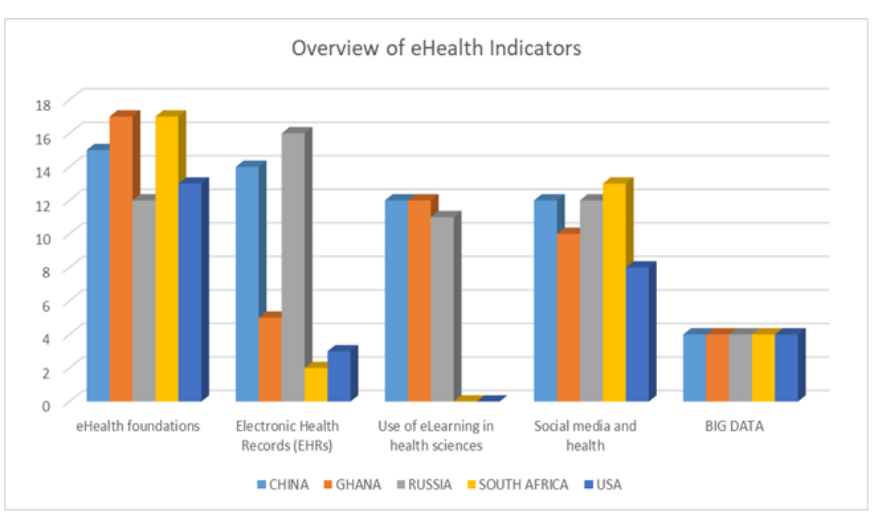

Figure 3. Overview of eHealth Indicators

\subsection{National Policies and Strategies: eHealth foundations}

The eHealth foundation provided some of the fundamental building blocks required to create an enabling environment for eHealth adoption. This includes a selection of indicators on eHealth-related policies or strategies, funding, multilingualism and 
capacity building. Data were reported by the individual country's responses (yes, no or don't know), percentage of source of funding across the five selected countries, proportion of eHealth capacity building both for students (i.e. pre-service training in eHealth) and professionals (i.e in-service training) expressed as a percentage, and "year adopted" for the particular indicator in the case of national policies/strategies.

The findings indicated that there is an upsurge in the support the development and delivery of health systems with good information systems across the five selected countries as shown in table 1 below. The result showed that having an eHealth strategy/policies amongst these countries was becoming a norm; three out of the five selected countries (i.e. China, South Africa and Russia) reported that they had a health coverage policy/strategy in place. An even higher number of these countries (all five) reported they had a comprehensive eHealth policy in place that sort to address issues of how the use of ICT, eHealth, or telehealth could support their realization of the universal healthcare and ultimately increase life expectancy. In terms of the adoption national policy on Telehealth policy/strategy, only China and Russia had such a policy in place. This observation makes one wonder whether Telehealth policy/strategy are weak in those countries or it is simply that eHealth policy development is not yet at a stage where it is fully integrated as part of the overall strategy for health but viewed as a separate support function? Nevertheless, it would seem that the need to use ICT to underpin the information systems to deliver on universal healthcare is becoming widely recognized especially amongst BRICS countries.

\subsection{Funding}

Results on source of funding indicated that almost all countries had some sort of funding source to drive their eHealth adoption strategies. These funding were either from combination of sources, including public, private, donor/non-public or public-private partnerships. Responses from the five selected countries were very encouraging as most of them had public funding from their government ranging from between 25 percent to over 75 percent. Public funding for eHealth in China ranged between 25 to 50 percent, South Africa between 50 to 70 percent and Russia over 75 percent. These values shows the commitment of BRICS countries' government to improve the universal healthcare and consequently affecting the increase in life expectancy of their citizenry. In order to gain an informative perspective into the funding sources for eHealth programs, this study used the World Bank (The World Bank Group 2019) income group of each country. An interesting observation was made, that is, in upper-middle-income countries (South Africa and Russia), public sources of funding for eHealth programs were dominant, except China where public funding was between 20 to 50 percent. In lowermiddle income countries like Ghana, donor funding predominated (See appendix table 1).

\subsection{Capacity Building}

There is no denying the fact that the quality training and continuing professional development of students and health professionals both in-service training and pre-service training are essential for providing highquality eHealth services and ultimately achieving high life expectancy. These indicators captured under the eHealth capacity building helps to measure the preparedness of health students and professionals through training programs to use eHealth in clinical settings. As shown in table 1 (see appendix table 1), all countries reported that they have adopted eHealth tools (social media etc) in preparing health students for the roles after leaving school. In China, more than 75 percent was reported on capacity building for students in the health sciences for the adoption of eHealth, with Ghana and Russian recording between 50 to 70 percent 
in the eHealth capacity building of students. Interestingly, South Africa and USA reported less than 25 percent on the preparedness of health students to be able to adopt eHealth. For in-service adoption of eHealth, Ghana and Russia recorded between 50-70 percent while China and USA recorded 25 to 50 and less than 25 percent respectively. Given this, there is likely to be an increasing requirement for training on eHealth adoption amongst pre-service and in-service personnel amongst these countries. Though more needs to be done, it is encouraging that all of the selected countries are now offering training in ICT for health. Much of this training typically is focused on improving the management of information within the health system as reported by respondents. Unsurprisingly, a much more recent phenomena that is training in the use of social media in health is still an unfolding discussion. An exploratory question concerning whether there was a national policy to govern the use of social media in the health professions revealed that the vast majority of countries.

\subsection{Correlation and Regression Analyses}

Correlation and regression analyses were conducted to examine the relationship between Life expectancy at birth and various eHealth indicators; eHealth foundations, hospital bed density, total health expenditure, ICT development index rank, mobile cellular subscriptions, internet users, electronic health records, use of health eLearning in health sciences, social media and big data. The correlations were examined using holm corrections to adjust for multiple comparisons based on an alpha value of 0.05. A significant negative correlation was observed between total health expenditure and eLearning overview (rs = $-0.95, \mathrm{p}=.014)$. The correlation coefficient between total health expenditure and eLearning overview was 0.95 , indicating a large effect size. This correlation indicates that as total health expenditure increases, eLearning overview tends to decrease. A significant negative correlation was observed between ICT development index rank and internet users ( $r s=-1.00$, $\mathrm{p}<.001)$. The correlation coefficient between ICT development index rank and internet users was -1.00 , indicating a large effect size. This correlation indicates that as ICT development index rank increases, internet users tends to decrease. A significant negative correlation was observed between Life expectancy at birth and social media ( $\mathrm{rs}=-0.96, \mathrm{p}<.001$ ). The correlation coefficient between Life expectancy at birth and social media was 0.96 , indicating a large effect size. This correlation indicates that as Life expectancy at birth increases, social media adoption in eHealth tends to decrease. No other significant correlations were found. Table 2 (See appendix table 2) presents the results of the correlations.

Forward linear regression analysis (See appendix tables 3 to 5) was carried out to investigate whether eHealth foundations, hospital bed density, total health expenditure, ICT development index rank, mobile cellular subscriptions, internet users, electronic health records, use of health eLearning in health sciences, social media and big data could significantly predict Life expectancy at birth. The results of the regression indicated that the model explained $100 \%$ of the variance and that the model was a significant predictor of Life expectancy at birth with p-values less than 0.001 .

\section{CONCLUSION}

While the relationship between eHealth and universal healthcare coverage remains a key issue, so too is the relationship between eHealth and life expectancy at birth. One of the key tools in realizing the UN's sustainable development goals on attaining universal healthcare coverage which seeks to achieve universal healthcare coverage, including financial risk protection, access to quality essential health-care services and access to safe, effective, quality and affordable essential medicines and vaccines for all by 2030 (UN General Assembly 2015), is through the use 
of eHealth. The adoption of eHealth presents a unique opportunity to promote such a comprehensive and coherent approach to health, beyond the control of specific diseases, and also to help focus on how the health system delivers integrated, people-centered health services which will consequently increase the life expectancy of the general population (International Health Partnership 2016). In addition to supporting the growing information needs of clinicians and management working within or from health facilities through the use of ICT and eHealth, it is imperative for stakeholders to also role out programs and services targeted at the general populace to better position them to harvest the benefit of eHealth and ultimately increasing their access to fundamental healthcare which will help in achieving universal healthcare coverage and consequently attaining higher life expectancy. In doing so, stakeholders should explore how a people-centered health service can be supported by cross-sector work, and thereby lay the eHealth foundations for the future.

\section{REFERENCES}

[1]. Flygt, C., B. Homelius, B. Jacobsson, M. Foldevi and E. Trell (1995). "Essential data set for computer management of distributed primary care services." Medical Informatics 20(4): 331341.

[2]. Fontaine, P., S. E. Ross, T. Zink and L. M. Schilling (2010). "Systematic review of health information exchange in primary care practices." J Am Board Fam Med 23(5): 655-670.

[3]. International Health Partnership (2016). UHC 2030: Building an Alliance to Strengthen Health Systems Draft Concept Note-17 June 2016. Geneva:, International Health Partnership.

[4]. Kim, T. K. and S. R. Lane (2013). "Government health expenditure and public health outcomes: A comparative study among 17 countries and implications for US health care reform."
American International Journal of Contemporary Research 3(9): 8-13.

[5]. Pizziferri, L., A. F. Kittler, L. A. Volk, M. M. Honour, S. Gupta, S. Wang, T. Wang, M. Lippincott, Q. Li and D. W. Bates (2005). "Primary care physician time utilization before and after implementation of an electronic health record: a time-motion study." Journal of biomedical informatics 38(3): 176-188.

[6]. The General Assembly, U. N. (2015). Resolution A/RES/70/1: Transforming our world: The 2030 Agenda for Sustainable Development. New York (NY): United Nations, United Nations.

[7]. The World Bank Group. 2019. 'World Bank country classification', The World Bank Group. http://data.worldbank.org/about/country-andlending-groups.

[8]. van den Heuvel, W. J. and M. Olaroiu (2017). "How important are health care expenditures for life expectancy? A comparative, european analysis." Journal of the American Medical Directors Association 18(3): 276. e279-276. e212.

[9]. Van Lerberghe, W. (2008). The world health report 2008: primary health care: now more than ever, World Health Organization.

[10]. Wager, K. A., F. W. Lee, A. W. White, D. M. Ward and S. M. Ornstein (2000). "Impact of an electronic medical record system on communitybased primary care practices." The Journal of the American Board of Family Practice 13(5): 338348.

[11]. World Health Organization, WHO (1978). World Health Organization, Alma Ata Declaration. Geneva, World Health Organization.

[12]. World Health Organization, WHO (2015). Atlas of eHealth country profiles: the use of eHealth in support of universal health coverage: based on the findings of the third global survey on eHealth 2015. Geneva 27, Switzerland. 
[13]. World Health Organization, WHO (2015). WHO Global Health Observatory Data Repository 2015. Geneva, World Health Organization.

[14]. World Health Organization, WHO (2016). Global diffusion of eHealth: making universal health coverage achievable. Report of the third global survey on eHealth. Geneva, Switzerland.

[15]. World Health Organization, WHO (2017). BRICS Health and WHO, Country Presence Profile. Geneva, World Health Organization.

\section{Appendix}

Table 1. Comparison of Country Adoption of National Policies for eHealth, Health information Systems and Telehealth

\begin{tabular}{|c|c|c|c|c|c|c|c|c|c|c|}
\hline Indicator: & \multicolumn{5}{|c|}{ Country response } & \multicolumn{5}{|c|}{ Year adopted } \\
\hline Countries & PRC & GHA & USA & SA & RUS & PRC & GHA & USA & SA & RUS \\
\hline $\begin{array}{l}\text { Health } \\
\text { coverage } \\
\text { policy/strategy }\end{array}$ & YES & NO & NO & YES & YES & 2009 & N/A & $\mathrm{N} / \mathrm{A}$ & N/A & 1991 \\
\hline $\begin{array}{l}\text { eHealth } \\
\text { policy/strategy }\end{array}$ & YES & YES & YES & YES & YES & 2012 & 2010 & 2005 & 2012 & 2013 \\
\hline $\begin{array}{l}\text { HIS } \\
\text { policy/strategy }\end{array}$ & NO & NO & YES & YES & YES & N/A & N/A & 2015 & 2011 & 2011 \\
\hline $\begin{array}{l}\text { Telehealth } \\
\text { policy/strategy }\end{array}$ & YES & NO & NO & $\mathrm{NO}$ & YES & 2013 & N/A & N/A & $\mathrm{N} / \mathrm{A}$ & 2008 \\
\hline
\end{tabular}

\begin{tabular}{|c|c|c|c|c|c|c|c|c|c|c|}
\hline \multirow{2}{*}{$\begin{array}{l}\text { Funding } \\
\text { sources for } \\
\text { eHealth }\end{array}$} & \multicolumn{5}{|c|}{ Country response } & \multicolumn{5}{|c|}{ Percentage of funding source } \\
\hline & YES & $\mathrm{NO}$ & YES & YES & YES & $25-50$ & 0 & - & $50-75$ & $>75$ \\
\hline $\begin{array}{l}\text { Private or } \\
\text { commercial } \\
\text { funding }\end{array}$ & YES & YES & YES & NO & YES & $25-50$ & $<25$ & - & 0 & $<25$ \\
\hline $\begin{array}{l}\text { Donor/non- } \\
\text { public funding }\end{array}$ & YES & YES & NO & YES & YES & $<25$ & $50-75$ & - & $25-50$ & $<25$ \\
\hline $\begin{array}{l}\text { Public-private } \\
\text { partnerships }\end{array}$ & NO & YES & NO & YES & YES & 0 & $<25$ & - & 0 & $<25$ \\
\hline
\end{tabular}




\begin{tabular}{|c|c|c|c|c|c|c|c|c|c|c|}
\hline $\begin{array}{l}\text { eHealth } \\
\text { capacity }\end{array}$ & \multicolumn{5}{|c|}{ Country response } & \multicolumn{5}{|c|}{ Proportion } \\
\hline $\begin{array}{l}\text { Health } \\
\text { sciences } \\
\text { students }\end{array}$ & YES & YES & YES & YES & YES & $>75$ & $50-75$ & $<25$ & $<25$ & $50-75$ \\
\hline $\begin{array}{l}\text { Health } \\
\text { professionals }\end{array}$ & YES & YES & YES & NO & YES & $25-50$ & $50-75$ & $<25$ & N/A & $50-75$ \\
\hline
\end{tabular}

Note: PRC=People's Republic of China, GHA= Ghana, USA=United State of America, $S A=$ South Africa, RUS=Russia, HIS=Health information systems, N/A=Not Applicable, “- "=Unanswered

Table 2. Correlation Indicators

\begin{tabular}{lcc}
\hline Combination & $r s$ & $p$ \\
\hline Hospital bed density-Life expectancy at birth & 0.50 & .391 \\
Hospital bed density -Total health expenditure & 0.20 & .747 \\
Hospital bed density -ICT development index rank & -0.70 & .188 \\
Hospital bed density-Mobile cellular subscriptions & 0.10 & .873 \\
Hospital bed density-Internet users & 0.70 & .188 \\
Hospital bed density-eHealth foundation & -0.87 & .054 \\
Hospital bed density -EHRs Overview & 0.70 & .188 \\
Hospital bed density-eLearning overview & 0.00 & 1.000 \\
Hospital bed density-Social Media in health & 0.15 & .805 \\
Life expectancy at birth-Total health expenditure & 0.30 & .624 \\
Life expectancy at birth-ICT development index rank & -0.80 & .104 \\
Life expectancy at birth-Mobile cellular subscriptions & -0.60 & .285 \\
Life expectancy at birth-Internet users & 0.80 & .104 \\
Life expectancy at birth-eHealth foundation & -0.67 & .219
\end{tabular}


Combination

Life expectancy at birth-EHRs Overview

Life expectancy at birth-eLearning overview

Life expectancy at birth-Social Media in health

Total health expenditure-ICT development index rank

Total health expenditure-Mobile cellular subscriptions

Total health expenditure-Internet users

Total health expenditure-eHealth foundation

Total health expenditure-EHRs Overview

Total health expenditure-eLearning overview

Total health expenditure-Social Media in health

ICT development index rank-Mobile cellular subscriptions

ICT development index rank-Internet users

ICT development index rank-eHealth foundation

ICT development index rank-EHRs Overview

ICT development index rank-eLearning overview

ICT development index rank-Social Media in health

Mobile cellular subscriptions-Internet users

Mobile cellular subscriptions-eHealth foundation

Mobile cellular subscriptions-EHRs Overview

Mobile cellular subscriptions-eLearning overview

Mobile cellular subscriptions-Social Media in health

Internet users-eHealth foundation

Internet users-EHRs Overview
0.30

0.00

$-0.96$

$-0.70$

0.10

0.70

$-0.36$

$-0.50$

$-0.95$

.014

$-0.05$

.935

0.10

.873

$-1.00$

0.87

.054

$-0.20$

.747

0.47

0.36

.553

$-0.10$

.873

$-0.15$

.805

0.10

.873

$-0.32$

.604

0.41

.493

$-0.87$

.054

0.20

.747 


\begin{tabular}{lcc}
\hline Combination & $r s$ & $p$ \\
\hline Internet users-eLearning overview & -0.47 & .420 \\
Internet users-Social Media in health & -0.36 & .553 \\
EHealth foundation-EHRs Overview & -0.62 & .269 \\
EHealth foundation-eLearning overview & 0.16 & .794 \\
EHealth foundation-Social Media in health & 0.26 & .669 \\
EHRs Overview-eLearning overview & 0.63 & .252 \\
EHRs Overview-Social Media in health & -0.05 & .935 \\
ELearning overview-Social Media in health & -0.08 & .897
\end{tabular}

Note. The confidence intervals were computed using $\alpha=0.05 ; n=52$; Holm corrections used to adjust $p$-values.

Table 3. Model Summary

\begin{tabular}{ccc}
\hline Model & $\mathbf{R}$ & R Square \\
\hline 1 & $1.000 \mathrm{a}$ & 1.000 \\
a. Predictors: (Constant), Social Media in Health, eLearning Overview, Hospital bed density & \\
\hline
\end{tabular}

Table 4. ANOVAa

\begin{tabular}{ccccccc}
\hline & Model & Sum of Squares & df & Mean Square & F & Sig. \\
\hline & Regression & 252.750 & 3 & 84.250 & 0.000 & $0.000 \mathrm{~b}$ \\
1 & Residual & .000 & 0 &. & & \\
& Total & 252.750 & 3 & &
\end{tabular}

a. Dependent Variable: LIFE EXPECTANCY AT BIRTH
b. Predictors: (Constant), Social Media in Health, eLearning Overview, Hospital bed density

Table 5. Coefficients ${ }^{\mathrm{a}}$

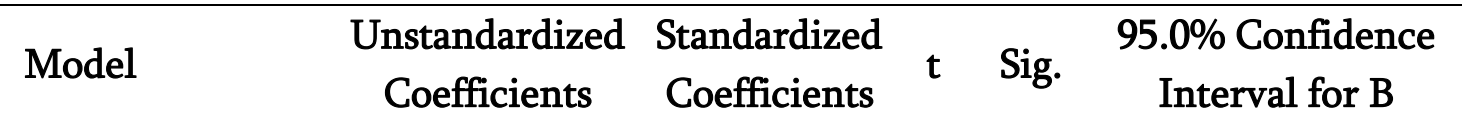




\begin{tabular}{|c|c|c|c|c|c|c|c|}
\hline & B & $\begin{array}{l}\text { Std. } \\
\text { Error }\end{array}$ & Beta & & & $\begin{array}{l}\text { Lower } \\
\text { Bound }\end{array}$ & $\begin{array}{l}\text { Upper } \\
\text { Bound }\end{array}$ \\
\hline (Constant) & 90.148 & .000 & & . & . & 90.148 & 90.148 \\
\hline Hospital bed density & .580 & .000 & .862 & . & . & .580 & .580 \\
\hline eLearning Overview & 3.314 & .000 & .208 & • & . & 3.314 & 3.314 \\
\hline Social Media in Health & -42.817 & .000 & -.862 & • & . & -42.817 & -42.817 \\
\hline Dependent Variable: LIFE E & $T A N$ & $B I R^{\prime}$ & & & & & \\
\hline
\end{tabular}

\section{Cite this article as :}

Ebenezer Ebenezer Larnyo, Baozhen Dai, Abigail Larnyo, Christabel Seyram Ankah, "eHealth Adoption and its Impact on Life Expectancy : A Comparative Study of Selected BRICS Countries plus TWO", International Journal of Scientific Research in Science and Technology (IJSRST), Online ISSN : 2395-602X, Print ISSN : 2395-6011, Volume 7 Issue 2, pp. 470-481, March-April 2020. Available at doi : https://doi.org/10.32628/IJSRST207286 Journal URL : http://ijsrst.com/IJSRST207286 